\title{
DETERMINATION OF PREDICTIVE FACTORS OF CHOLEDOCHOLITHIASIS IN CASES OF ACUTE BILIARY PANCREATITIS
}

Choledocholithiasis (bile duct stones) may bring about biliopancreatic obstruction that eventually develops into acute biliary pancreatitis, which could become a serious, life threatening disease. Because stones have the propensity to move spontaneously from the bile duct, it is allimportant to determine as accurately as possible, whether biliopancreatic obstruction is still present or not. The aim is to avoid, wherever possible, any invasive and costly diagnostic and therapeutic procedures while preventing serious risk to the patient. In this paper, by retrospective analysis of patients with acute biliary pancreatitis, we examine laboratory and other parameters, obtained by quick and easy to implement non-invasive methods, for to determine predictive factors of biliopancreatic obstruction. Our results indicate that the definite predictive parameter for choledocholithiasis is previous cholecystectomy and the dilation of the bile duct. Supporting predictive factors are bilirubin and alanine aminotransferase.

Key words: acute biliary pancreatitis, endoscopic retrograde cholangiopancreatography, Chi-square tests.

Abbreviations: $A B P$, acute biliary pancreatitis; $A L P$, alkaline phosphatase; $A L T$, alanine aminotransferase; $A S T$, aspartate aminotransferase; Bi, bilirubin; CBDS, common bile duct stone; EPS, endoscopic papilosphincterotomy; ERCP, Endoscopic retrograde cholangiopancreatography; EUS, endoscopic ultrasonography; GMT, gamma-glutamyl transferase; IOC, intraoperative cholangiography; MRCP, magnetic resonance cholangiopancreatography; N, reference value; NS, not significant; ROC, Relative Operating Characteristic; USG, ultrasonography.

\section{Introduction}

Gallstone (cholelithiasis) disease is a very common condition involving roughly $15 \%$ of the population in Europe. In $10 \%$ to $15 \%$ of cases, cholelithiasis is complicated by the presence of common bile duct stones. Gallstone migration through the biliary tract can cause acute pancreatitis [1]. In many cases biliopancreatic obstruction is transient because the offending stone passes rapidly into the duodenum; otherwise persisting obstruction occurs due to the continued presence of a main bile duct stone or to ampullary edema following stone passage [2]. Biliary pancreatitis can be presumed when abdominal USG confirms gallblader or bile duct stones and, in particular, when serum hepatic transaminases are acutely increased in the initial presentation, and alcohol is reliably excluded [3]. Early therapeutic ERCP reduces complications among acute pancreatitis patients who have biliary obstruction $[1,4]$. Because stones have a propensity to move spontaneously from the bile duct, the important question to be answered in all cases of $\mathrm{ABP}$ is whether or not a calculous biliary obstruction is still present. Answering this question conditions subsequent management, including the need for ERCP and EPS or surgical procedures, IOC, choledochotomy or non-invasive tests, MRCP, and EUS [1]. Employing non-invasive, widely used and readily available tests, we endeavoured to establish predictive factors-predictors, which would predict the presence of common bile duct stone in patients with $\mathrm{ABP}$ with the highest probability.

\section{Patients and methods}

Our aim was to examine in patients with $\mathrm{ABP}$ the relationships between persistent CBDS and values of their laboratory parameters, and with dilation of their bile duct to find significant associations.

For this purpose we retrospectively, in two stages, statistically evaluated the database of total 130 consecutive patients with ABP referred from Martin Faculty Hospital, Internal Gastroenterology Clinic, Martin, Slovakia in the years 1999-2008.

Stage 1. Patients from 1999 to 2003, had received early ERCP (within 48 hours) at the time when we had not had the possibility to perform MRCP and EUS regularly. These patients, group I, $n=76$, (20 men and 56 women $)$ mean age $60.1 \pm 16.3$ years (range 24 - 92) were used to determine predictors for CBDS. Analysis was performed on the whole group.

\footnotetext{
* Marta Horakova ${ }^{1}$, Iveta Vadovicova ${ }^{2}$

${ }^{1}$ Internal Gastroenterology Clinic, Martin Faculty Hospital, Martin, Slovakia, E-mail: martahorakova@zoznam.sk

${ }^{2}$ Department of Mathematics, Faculty of Science, University of Zilina, Slovakia,
} 
We studied following factors: age, dilation of the common bile duct, and laboratory parameters, specifically Bi, ALT, which had been done to all the patients prior to ERCP, as well as GMT, AST, ALP and dependence of CBDS occurrence from previous cholecystectomy. Pathologic laboratory values were considered to be higher than the reference values $(\mathrm{N}): B i>22.2 \mu \mathrm{mol} / 1, A S T>$ $>0.66 \mu \mathrm{kat} / 1, A L T>0.66 \mu \mathrm{kat} / 1, G M T>0.82 \mu \mathrm{kat} / 1, A L P>2.6$ $\mu \mathrm{kat} / \mathrm{l}, A M S>3.7 \mu \mathrm{kat} / \mathrm{l}$. The presence of CBDS and the common bile duct diameter were determined by ERCP or by IOC in patients where ERCP was unsuccessful. In ERCP we considered the bile duct dilated when the diameter was $10 \mathrm{~mm}$ or more. Prior to ERCP we employed ultrasound to determine the common bile duct diameter. With ultrasonography, we considered the bile duct dilated when the diameter was more than $7 \mathrm{~mm}(9 \mathrm{~mm}$ and more after cholecystectomy).

The associations between the presence of CBDS and bile duct dilation or the values above the mentioned laboratory parameters or previous cholecystectomy were investigated by dividing patients into two sub groups: with CBDS and without CBDS. Their quantitative data (values of laboratory parameters) were compared using Student's $t$-test. For each significant variable on the $t$-test, using ROC curve, we determined the cut-off value as a multiple of the normal value of the relevant parameter. Thus we obtained two categorical variables, which were compared by the $\chi^{2}$ test of independence, and logistic regression. Using $\chi^{2}$ test of independence we also investigated the association between occurrence of CBDS and dilation of common bile duct or previous cholecystectomy. For small groups of patients we used Fisher's exact test; logit confidence intervals for the odds ratio was calculated using the method of Alan Agresti [5]. We considered p-values $\leq 0.05$ as statistically significant.

Because the prevalence of choledocholithiasis increases with age, [1], and an interaction appeared between the age and other predictors, the multivariate analysis was performed separately for patients older and younger than 70 years.

\section{Results}

The prevalence of choledocholithiasis in patients $\leq 70$ years old with ABP (52 patients, mean age $51.8 \pm 12.1$ years) was $36.5 \%(19 / 52)$, in patients $>70$ years old (24 patients, mean age $78.3 \pm 5.9$ years $)$ was $54.2 \%(13 / 24)$.

We determined the following significant associations:

Bile ducts dilation. The probability of the presence of a stone in the bile ducts if the bile ducts are dilated was $66.7 \%(28 / 42)$, in the absence of bile duct dilation the probability of CBDS occurrence was $11.7 \%(4 / 34)$, sensitivity $87.5 \%$, specificity $68.2 \%, p<$ $<0.001$.

Bilirubin. Bilirubin is examined on all patients with $\mathrm{ABP}$. We did not find a statistically significant association between the $\mathrm{Bi}$ level and CBDS occurrence even after dividing patients by age. Therefore, we explicated some other medical factors, which could have influenced the value of $\mathrm{Bi}$, hence adversely affected achievement while determining the association between persisting CBDS and increased level of $\mathrm{Bi}$. It was established that if we from the tested group of patients excluded all these with acute cholecystitis and cholangitis (diagnoses with increased value of $\mathrm{Bi}$ ) a significant association would exist between the CBDS occurrence and bilirubin level in the whole patients group, not divided by age, with dilated bile ducts. The probability of CBDS occurrence for bilirubin level $>1.5 \mathrm{~N}$ is $81.8 \%(18 / 22)$ and for bilirubin level $<1.5 \mathrm{~N}$ is $50 \%(6 / 12)$. Sensitivity $75 \%$, specificity $60 \%, p=0.05$.

ALT. We found a statistically significant association between CBDS occurrence and ALT activity only after dividing the whole patients group into two subgroups according to their age. In patients $\leq 70$ years old with dilated bile ducts and $3 \mathrm{~N}<$ ALT $<7 \mathrm{~N}$ or ALT $>12 \mathrm{~N} \mathrm{CBDS}$ is present in $81.3 \%(13 / 16)$ and in $20 \%(2 / 10)$ for other values of ALT. Sensitivity $86.7 \%$, specificity $72.7 \%$, $p<0.004$.

For the patients $\leq 70$ years old without acute cholecystitis with not dilated bile ducts we found an association between the CBDS occurrence and bilirubin level together with ALT activity. For $\mathrm{Bi}>1.5 \mathrm{~N}$ occurring with an ALT $>8 \mathrm{~N}$ CBDS is present in $33.3 \%(4 / 12)$ and in $0 \%(0 / 9)$ for $\mathrm{Bi}<1.5 \mathrm{~N}$ or ALT $<8 \mathrm{~N}$. Sensitivity $100 \%$, specificity $52.9 \%, \mathrm{p}=0.08(\mathrm{NS})$.

As for patients with bile ducts dilation with CBDS occurrence we found the dependence of ALT activity on age. The median of ALT for these patients $\leq 50$ years old is $10.6 \mu \mathrm{kat} / 1$ and for patients $>50$ years old median of ALT is $2.9 \mu \mathrm{kat} / \mathrm{l}$. The mean difference is statistically significant, $p<0.05$.

We did not find a statistically significant association between the ALT activity and CBDS occurrence at patients $>70$ years old. Even patients with dilated bile ducts had CBDS also in the case of ALT $<3 \mathrm{~N}$, while ALT $>3 \mathrm{~N}$ is one of symptoms by ABP.

GMT. A bile duct stone is present in 100\% (8/8) of patients $>70$ years old with dilated bile ducts and GMT $>5 \mathrm{~N}$, and in $25 \%$ $(1 / 4)$ with GMT $<5 \mathrm{~N}$ and with dilated bile ducts.

Sensitivity $88.9 \%$, specificity $100 \%, p=0.02$.

We did not find a statistically significant association between the GMT activity and CBDS occurrence at patients $\leq 70$ years old; but, not everybody in this group had GMT examined before ERCP.

Previous cholecystectomy. By patients with previous cholecystectomy CBDS was present in $81.8 \%$ (9/11). Sensitivity $28.1 \%$, specificity $95.5 \%, p=0.005$.

Stage 2. The results we obtained by studying the associations between CBDS and laboratory parameters, previous cholecystectomy, [6], and dilated bile duct on the group I, were verified on the control group of patients with ABP treated in the MNF hospital in Martin in the years 2004-8, group II, which consisted of 54 patients ( 19 men and 34 women) mean age $63.5 \pm 16.3$ years (range 
CBDS significant predictors for patients with ABP

Table 1

\begin{tabular}{|l|l|c|c|c|}
\hline Patients & Predictor & \% CBDS & Odds ratio (95\% CI) & pValue \\
\hline entire group & previous cholecystectomy & 81.8 & $8.0(3.5$ to 18.2$)$ & 0.005 \\
\hline entire group & bile duct dilation & 66.7 & $15.0(4.5$ to 48.8$)$ & $<0.001$ \\
\hline without acute cholecystitis with bile duct dilation & Bi $>1.5 \mathrm{~N}$ & 81.8 & $4.2(0.9$ to 18.3$)$ & 0.05 \\
\hline age $\leq 70$ years with bile duct dilation & $3 \mathrm{~N}<$ ALT $<7 \mathrm{~N}$ or $12 \mathrm{~N}<$ ALT & 81.3 & $17.3(5.2$ to 34.0$)$ & 0.004 \\
\hline age $>70$ years with bile duct dilation & GMT $>5 \mathrm{~N}$ & 100 & $57.6(7.6$ to 435.4$)$ & 0.002 \\
\hline
\end{tabular}

24-86). By using $t$-test, and $\chi^{2}$ - "goodness of fit" test, respectively, we found that the difference in age composition in both groups I and II, and the difference between observed and expected probabilities of CBDS occurrence depending on bile duct dilation, values of ALT, Bi and previous cholecystectomy in the group II, resp., is not significant. The value of test criteria $\chi^{2}$ equals $1.041<$ $<\chi_{0.05}^{2}(3)=7.81$.

Comparison of observed and expected probabilities of CBDS occurrence for the group II

Table 2

\begin{tabular}{|l|l|c|c|}
\hline Patients & Predictor & $\begin{array}{c}\text { observed \% } \\
\text { of CBDS }\end{array}$ & $\begin{array}{c}\text { expected \% } \\
\text { of CBDS }\end{array}$ \\
\hline entire group & $\begin{array}{l}\text { previous cholecys- } \\
\text { tectomy }\end{array}$ & 66.7 & 81.8 \\
\hline entire group & bile duct dilation & 78.9 & 66.7 \\
\hline $\begin{array}{l}\text { without acute cholecysti- } \\
\text { tis with bile duct dilation }\end{array}$ & $\mathrm{Bi}>1.5 \mathrm{~N}$ & 71.4 & 81.8 \\
\hline $\begin{array}{l}\text { age } \leq 70 \text { years with } \\
\text { bile duct dilation }\end{array}$ & $\begin{array}{l}3 \mathrm{~N}<\mathrm{ALT}<7 \mathrm{~N} \\
\text { or } 12 \mathrm{~N}<\mathrm{ALT}\end{array}$ & 100 & 81.3 \\
\hline
\end{tabular}

\section{Discussion}

Bilirubin and ALT were tested for every patient before ERCP. Bilirubin level was influenced by the presence of acute cholecystitis and by the presence of acute cholangitis, while patients with acute cholangitis also had acute cholecystitis. Even without detectable common bile duct obstruction, acute cholecystitis often causes mild elevations in the serum bilirubin concentrations. The elevated bilirubin level may be a consequence of haemathogenous or direct spread infection, which may cause structural and functional abnormalities of the liver. Since the patients with acute cholecystitis had elevated bilirubin levels even when CBDS was not present, the relationship between bilirubin level and CBDS was significant in patients with bile duct dilations after eliminations of patients with acute cholecystitis only.
We found the age to be a factor influencing ALT activity in patients with CBDS and bile duct dilation. Younger patients had higher ALT activity, older patients had elevated ALT activity but of a lesser degree than the younger ones. Two intervals of ALT values, as predictors of CBDS, are probably the result of age-dependent ALT activity as well as of possible spontaneous movement of the stones.

\section{Conclusion}

ERCP is indicated at patients with suspicion of ABP if biliary obstruction is present and if the presence of ductal stone is suspected. ERCP should have been used selectively because it is difficult, bothersome, expansive and has the potential of causing further pancreatic damage.

By using predictors we had established it is now possible to categorize patients according to the likelihood of CBDS occurrence. Providing predictive factors of biliary obstruction are not present it is useful to perform a less invasive or non-invasive investigation of bile ducts (EUS, MRCP), and ERCP and subsequent sphincterotomy should be indicated only if the presence of CBDS is confirmed by these methods.

Our results manifest that the definite predictive factor for CBDS is previous cholecystectomy and the bile duct dilation. Supporting predictors of these laboratory parameters, which were tested for every patient before ERCP, by patients with dilated bile ducts, influencing the probability of CBDS occurrence are the value of ALT in patients $\leq 70$ years old and the level of Bi by patients without acute cholecystitis and cholangitis.

\section{Acknowledgement:}

This research has been supported by the Slovak Grant Agency VEGA through the project No. 1/0867/08.

\section{References}

[1] PRAT, F., MEDURI, B., DUCOT, B. et al.: Prediction of Common Bile Duct Stones by Noninvasive Tests. Annals of surgery, 229, 1999, 3, pp. 362-8. 
[2] ORIA, A., CIMMINO, D., OCAMPO, C. et al.: Early Endoscopic Intervention Versus Early Conservative Management in Patients with Acute Gallstone Pancreatitis and Biliopancreatic Obstruction: A randomized clinical trial, Ann Surg 245, 2007, (1), pp. $10-17$.

[3] NORTON, I.D., PETERSEN, B.T.: Acute and Chronic Pancreatitis Interventional Treatment of Acute and Chronic Pancreatitis, Endoscopic procedures. Surg Clin North Am, 79, 1999, 4, pp. 896-911.

[4] MARK, D.H., LEFEVRE, F., FLAMM, C.R.et al: Evidence-based Assessment of ERCP in the Treatment of Pancreatitis. Gastrointest Endosc, Supplement to: 56, 2002, 6, pp. 249-54.

[5] AGRESTI, A., LOGIT, O.: Confidence Intervals for the Odds Ratio with Small Samples. Biometrics 55, 1999, pp. 597-602.

[6] HORAKOVA, M., VADOVICOVA, I., KATUSCAK, I., JANIK, J., MAKOVNIK, P., SADLONOVA, J.: Consideration of Endoscopic Retrograde Cholangiopancreatography in Cases of Acute Biliary, Pancreatitis. Bratislava Medical Journal. Vol. 10, No. 9, 2009, pp. 553-558. 